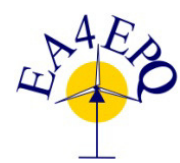

International Conference on Renewable Energies and Power Quality (ICREPQ'16)

Madrid (Spain), $4^{\text {th }}$ to $6^{\text {th }}$ May, 2016

Renewable Energy and Pourer Qualily. Fournal (RE\&PQJ)

ISSN 2172-038 X, No.14 May 2016

\title{
Analysis on Stability in Control of Active Power Filter in Electric Grid with Megawatt DFIG Wind Farm Connected
}

\author{
Nguyen Gia Minh Thao ${ }^{1}$, Kenko Uchida ${ }^{1}, K$ Kentaro Kofuji ${ }^{2}$, Toru Jintsugawa ${ }^{2}$, and Chikashi Nakazawa ${ }^{2}$ \\ ${ }^{1}$ Department of Electrical Engineering and Bioscience, School of Advanced Science and Engineering \\ Waseda University, Tokyo 169-8555, Japan \\ Phone number: +81 35286 3366, E-mail: thao@uchi.elec.waseda.ac.jp \\ ${ }^{2}$ Power System Analysis Section, Energy Solution Development Department \\ Fuji Electric Co., Ltd, Tokyo 191-8502, Japan \\ E-mail: kofuji-kentaro@fujielectric.com
}

\begin{abstract}
.
This paper presents a pretty comprehensive analysis on stability issues of control for active power filter (APF) installed in an electric grid where megawatt doubly fed induction generator (DFIG) wind farm is connected. Major objectives of this paper are to evaluate roles and impacts of main design parameters in the controller of APF. As well, the ultimate goal is to determine the stable value range and the suitable-performance value range for a proportional control coefficient in APF. Wherein, firstly, background theories of the voltage-detection control method for APF to reduce the voltage and current distortions on the electric grid are described. Furthermore, an appropriate equivalent circuit of a typical grid-connected DFIG wind farm with APF to analyze impedance in the frequency domain is introduced. After that, mathematical formulas and algorithm to determine the stable value range and suitable performance value range for the control coefficient in APF are proposed. Finally, results obtained with the suggested equivalent circuit and impedance analysis technique are shown and discussed in detail. Besides, different operation cases of the controller of APF and the illustrative DFIG wind farm, including parametric uncertainties of the electric grid, also are examined to assess effectiveness of the proposed analysis algorithm.
\end{abstract}

\section{Key words}

Megawatt grid-connected wind farm, DFIG, control of active power filter, stability analysis, Bode and Nyquist diagrams.

\section{Introduction}

Nowadays, according to [1], the doubly fed induction generator (DFIG), which has many salient advantages, is broadly used in large-scale wind farms to supply energy to electric grid. Nonetheless, power-electronic converters utilized with DFIG often produce and inject many harmonics into the grid; and this causes to boost the voltage and current distortions at the point of common coupling (PCC). As a consequence, in megawatt gridconnected wind farms, where many DFIGs are utilized, the total harmonic distortion (THD) value of grid voltage at PCC will exceed significantly over the acceptable value ranges recommended in $[2,5]$. Therefore, active power filter (APF) has been widely utilized to install at the PCC to diminish remarkably the harmonic problems in the electric grid where DFIG wind farms connected; of course, its ultimate goal is to maintain and ensure THD value of grid voltage in the acceptable ranges. Therein, determining and fine-tuning for the design parameters of APF in use clearly have large effects on the dynamic characteristics of the overall power system, especially on performance and stability.

Studies in [2]-[6] have performed analyses on impacts of the proportional control coefficient $K_{V}$ of APF on reducing the harmonic resonances in a general electric grid. Wherein, the higher value of $K_{V}$ have been recognized to have the better efficiency in harmonic reduction [3]; and if the value of $K_{V}$ is changed, this also makes to shift the orders of harmonic resonances in the electric grid [4]. Besides, authors in [7] has analyzed and evaluated main effects of design parameters of the filters utilized in the controller for APF (such as the cutfrequency and time-delay values) on performance and stability of the overall power system. However, as common drawbacks, the above analysis studies have not yet been proposed mathematical formulas and detailed algorithm to determine relatively the acceptable maximum value for $K_{V}$ (called as $K_{V-\max }$ ); and impacts of filters and time-delay value in the controller of APF on the acceptable value for $K_{V \text {-max }}$ also have not yet been considered carefully. In addition, the above analyses almost only have focused on APF installed in a general power system without detailed considerations about large-scale grid-connected DFIG wind farms. 
Motivated by the above reviews, this study introduces an analysis study on stability problems in control of APF, which focuses on the following key contents:

i. An equivalent model for study on harmonics, which can represent for a typical megawatt gridconnected DFIG wind farm with APF integrated at PCC, is presented.

ii. Then, main roles of the control coefficient $K_{V}$ in APF on stability of the overall power system are analyzed and evaluated. In detail, two main issues are examined as follows: how to determine the stable value range for $K_{V}$ to ensure stability of the system? And then, how to suggest the suitable-performance value range for $K_{V}$ in which configuration of the power system is considered?

iii. Besides, impacts of the time-delay value and the low-pass filter in the controller for APF on stability of the power system are also analyzed.

iv. Lastly, effects of physical parameters of the power system (such as: the length of transmission cable, and the number of DFIGs in wind farm) on the stable value range and suitable-performance value range of the coefficient $K_{V}$ are examined.

\section{Equivalent Circuit Model of Megawatt DFIG Wind Farm with APF Connected}

The illustrative power system, including the megawatt DFIG wind farm and APF, is shown in Figs. 1-2. In detail, each node in the low-voltage (LV) side includes a $2 M W$ DFIG, an R-C filter, and a transformer used to transmit power. Then, on the medium-voltage (MV) bus, many nodes are connected in parallel by transmission cables. At the PCC, an APF is installed to reduce efficiently the voltage and current distortions; lastly, a high-power transformer at the sub-station is used to transmit the electric power from the MV bus to the external main grid.

\subsection{Voltage-Detection Control Method for APF}

Referring in [2, 3], from the measured grid voltage at PCC $v_{g}$, the filters are utilized to extract the harmonic components of the measured grid voltage, $\tilde{v}_{g}(h)$; then, the reference current for $\operatorname{APF} i_{A P F}^{*}(h)$ is calculated as the obtained harmonic component $\tilde{v}_{g}(h)$ multiplied by the proportional control coefficient $K_{V}$ as follows:

$$
i_{A P F}^{*}(h)=K_{V} \times \tilde{v}_{g}(h)
$$
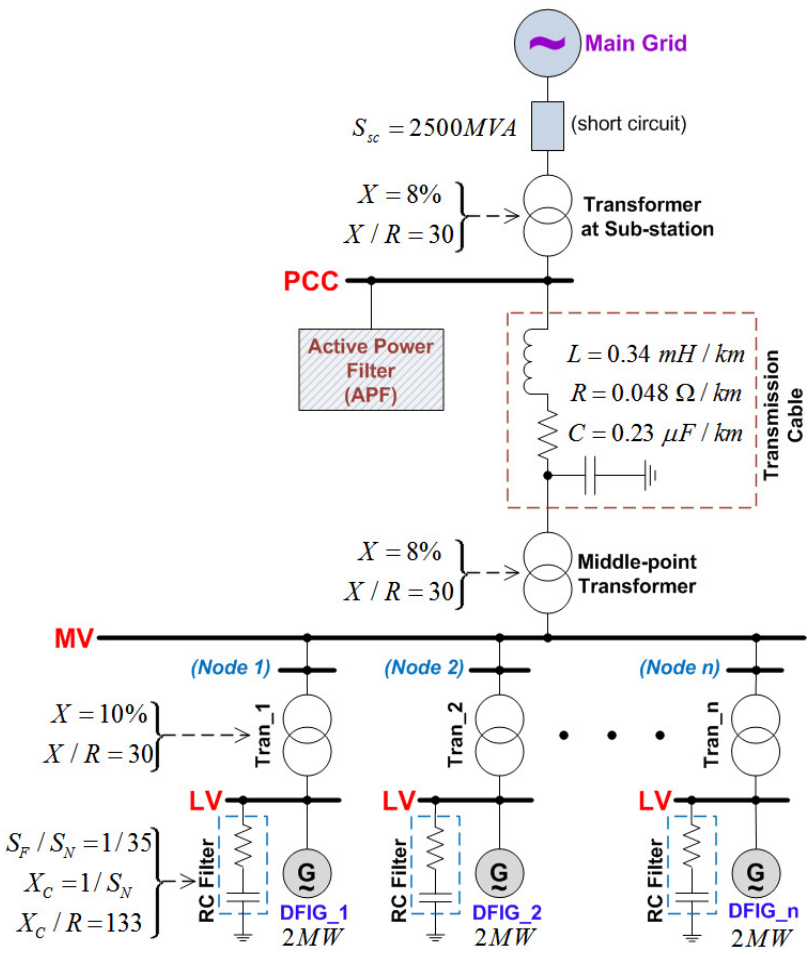

Fig. 1. The demonstrative power system utilized in this study.

As shown in Fig. 2(b), the time-delay block represents for all delay times of voltage measurement, filters and control of power-electronic converters in APF. Roles of the control coefficient $K_{V}$, filters and delay times in APF are important for stability of the power system [9-13].

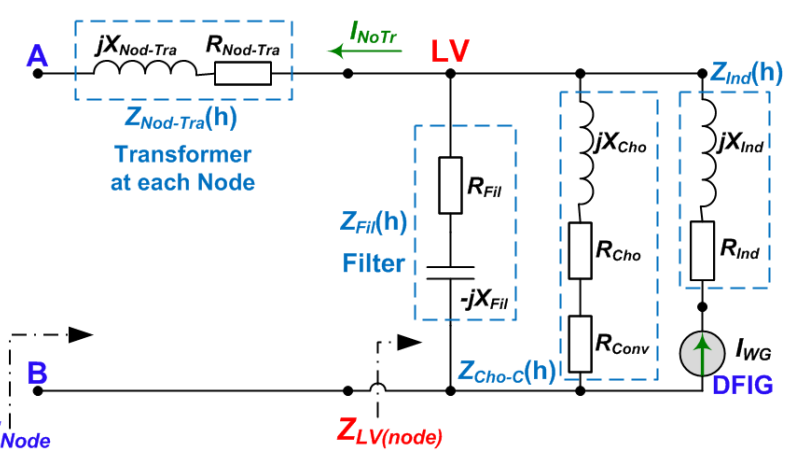

Fig. 2(a). Equivalent model for each DFIG node in wind farm.

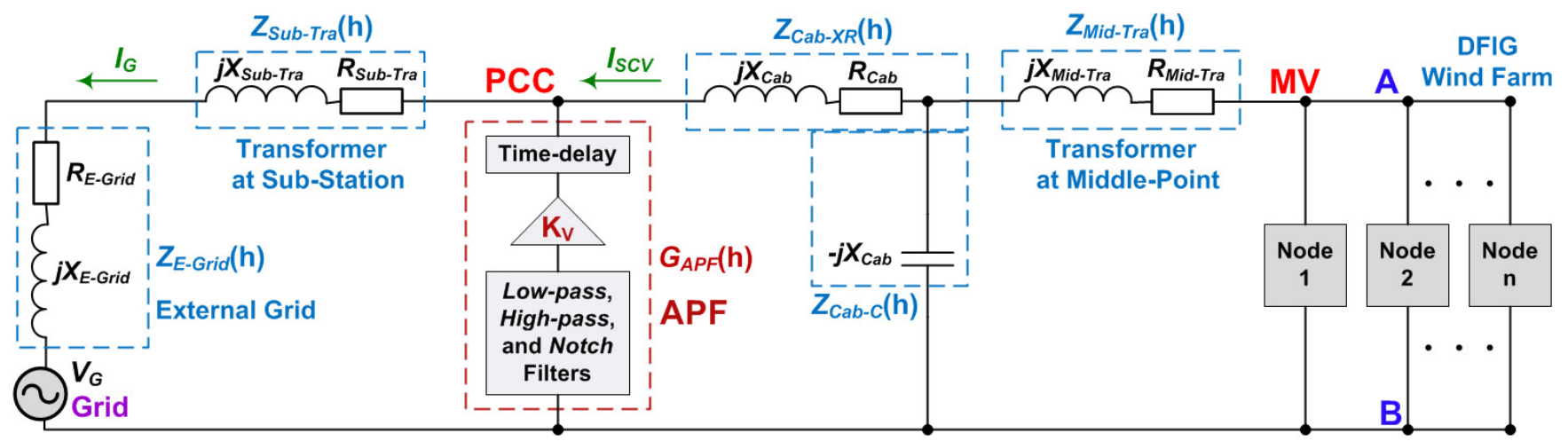

Fig. 2(b). The equivalent circuit model on harmonic resoance study for the demonstrative power system in Fig. 1. 


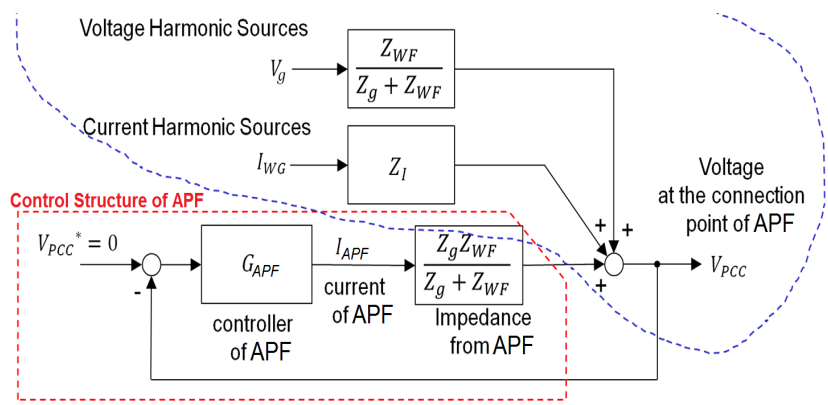

Fig. 3. Impedance analysis model seen from APF and sources.

\subsection{Formulas to Analyze the Harmonic Resonances}

According to [1, 3, 9] and Figs. 1-3, series resonances are generated by the harmonic voltage source $V_{E \text {-grid }}$ of the external main grid; and then it makes voltage distortions on the PCC and MV bus. Meanwhile, parallel resonances are produced by the harmonic current source $I_{W G}$ of each DFIG; and it causes large distortions of currents running through capacitor components on the MV bus (transmission cables) and the PCC.

$$
\begin{aligned}
& \left\{\begin{array}{l}
Z_{A B}(h)=1 / \sum_{i=1}^{n}\left(\frac{1}{Z_{\text {Node }}^{(i)}(h)}\right) \\
Z_{\text {Node }}^{(i)}(h)=Z_{\text {Nod-Tra }}+\left[Z_{\text {Fil }} / / Z_{\text {Cho-C }} / / Z_{\text {Ind }}\right]
\end{array}\right. \\
& Z_{A B[M V]}(h)=\left(Z_{\text {Nod-Tra }} / n\right)+\left[\left(Z_{F i l} / / Z_{C h o-C} / / Z_{\text {Ind }}\right) / n\right] \\
& Z_{W F}(h)=Z_{C a b-X R}+\left[Z_{C a b-C} / /\left(Z_{M i d-T r a}+Z_{A B[M V]}\right)\right] \\
& Z_{G}(h)=Z_{E-G r i d}+Z_{S u b-T r a} \\
& Z_{P S}(h)=Z_{G}+Z_{W F} \\
& Z_{E q u i[H V]}=Z_{C a b-C} / /\left\langle Z_{C a b-X R}+\left\{1 /\left[G_{A P F}+\left(1 / Z_{G}\right)\right]\right]\right\rangle \\
& \left.Z_{C o l[H V]}=Z_{C a b-C} \times\left\langle Z_{C a b-X R}+\left\{1 /\left[G_{A P F}+\left(1 / Z_{G}\right)\right]\right\}\right)\right\rangle \\
& \frac{I_{\text {NoTr }}}{I_{W G}}=\quad 1 /\left\{1+1 /\left[Z_{F i l} \times\left(Z_{\text {Mid-Tra }}+Z_{\text {Nod-Tra }}+Z_{\text {Equi }[H V]}\right)\right]\right\}
\end{aligned}
$$

- Voltage and current distortions caused by source $V_{G}$ :

$$
\frac{V_{P C C}}{V_{G}}(h)=1 /\left\{1+\left[G_{A P F}+\left(1 / Z_{W F}\right)\right] \times Z_{G}\right\}
$$

$$
\frac{I_{S C V}}{V_{G}}(h)=\left(\frac{V_{P C C}}{V_{G}}\right) / Z_{W F}
$$

- Voltage and current distortions caused by source $I_{W G}$ :

$$
\begin{aligned}
& \frac{I_{S C V}}{I_{W G}}(h)=\left(-\frac{I_{\text {NoTr }}}{I_{W G}}\right) / 1+\left(1 / Z_{C o l[H V]}\right) \\
& \frac{V_{P C C}}{I_{W G}}(h)=\left(\frac{I_{S C V}}{I_{W G}}\right) /\left[G_{A P F}+\left(1 / Z_{G}\right)\right]
\end{aligned}
$$

Where a sample program in Matlab to compute $G_{A P F}$ seen in Fig. 3 and (7)-(13) can be performed as follows:

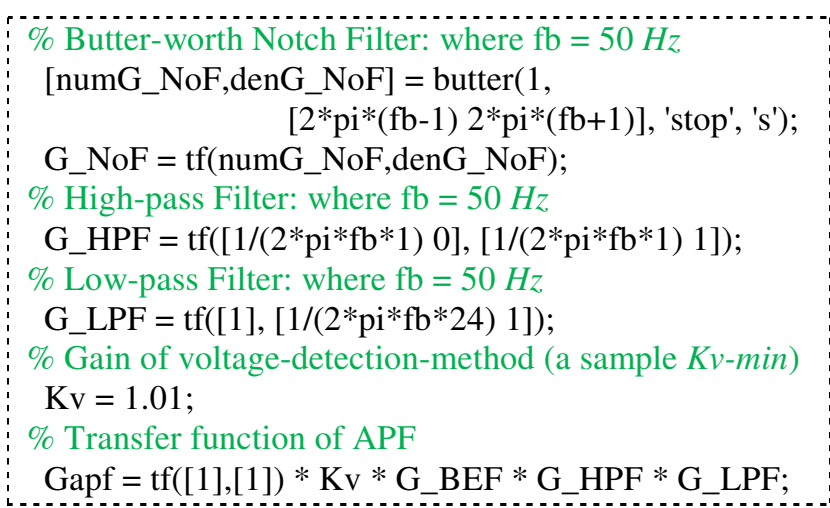

\section{Analysis Technique on Stability based on Theories of Bode and Nyquist Diagrams}

In Matlab, we can build a sample program to compute the gain margin and phase margin values [8] as follows:

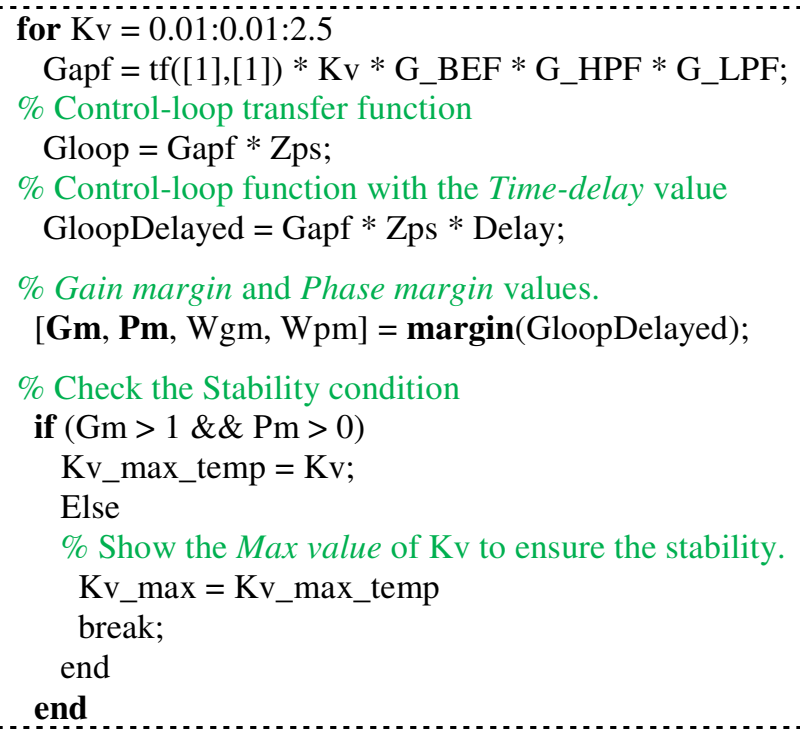

It is noted that the conditions used to determine the acceptable maximum value of $K_{V}$ ( called as $K_{V-\max }$ ) are 
according to the part (a) of Fig. 4. Of course, a facultative value in the range of $\left(\begin{array}{ll}0 & K_{V-\max }\end{array}\right]$ ensures stability of the overall control system. Besides, the acceptable minimum value for $K_{V}\left(0<K_{V-\min } \leq K_{V-\max }\right)$ also is necessary chosen not only to ensure stability of the system but also to reduce noticeably magnitudes of the resonances at PCC as much as possible.

According to the method introduced in [4] (with the lumped parameter model), the value of $K_{V \text {-min }}$ should be chosen to force the magnitude of voltage distortion as $\left|V_{p c c} / V_{g}\right| \leq 1$. However, as seen in the part (a) of Fig. 5, the background value of $\left|V_{p c c} / V_{g}\right|$ is already about 1 . Therefore, in this research of ours, instead of 1 , the new threshold limitation value can be chosen as follows:

$$
\left|V_{p c c} / V_{g}\right| \leq 2
$$

Similarly, we can choose an additional threshold limitation value for the current distortion as follows:

$$
\left|I_{s c v} / I_{w g}\right| \leq 4
$$

The above two equations in (14)-(15) will be utilized to determine relatively the acceptable minimum value for $K_{V}$ (called as $K_{V \text {-min }}$ ) where the performance of APF, in reducing the voltage and current distortions, are tolerable.

Finally, a Matlab program is built to analyze and determine automatically the key values as below. As seen Fig. 6, we have $K_{V-\min }=1.01, K_{V-\max }=1.25, h_{1}=4.6$ for voltage distortions, and $h_{1}=5.1$ for current distortions.

\footnotetext{
\% Threshold values are repsectively: $2,2,4$.

if $\left(\left(\operatorname{mag} \_V g \_V p c c \_m a x<=2\right)\right.$

$\& \&$ (mag_Iwg_Vpcc_max $<=2)$

$\& \&($ mag_Iwg_Iscv_max $<=4))$

$\mathrm{Kv} \_$min_temp $=\mathrm{Kv}$;

GloopDelayed_min $=$ Gapf $*$ Zps $*$ Delay;
}

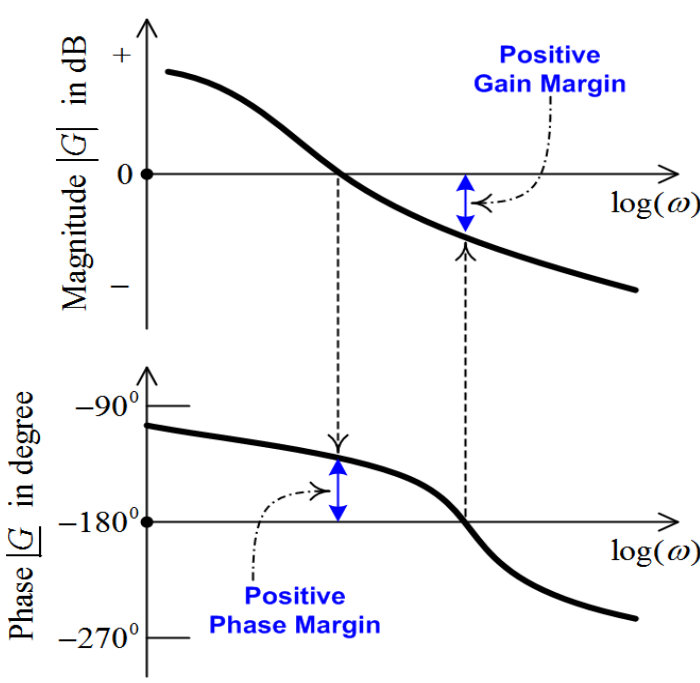

(a) Stable system

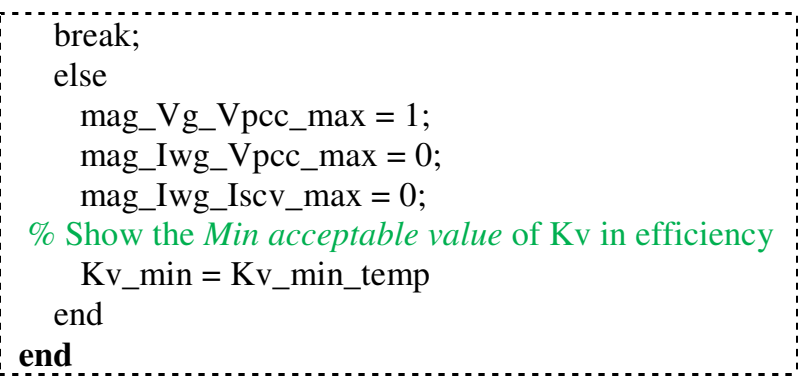

\section{Analysis Results in Matlab Simulation}

In this research, six different operation cases of the power system with grid-connected DFIG wind farm and APF in Fig. 1 are performed respectively as follows.

- Case 1: Test with open-loop controller where $K_{V}=0$.

- Case 2: Test with the closed-loop controller where $K_{V}=K_{V-\min }=1.01$ to evaluate performance of APF.

- Case 3: From Case 2, decrease the time-delay value in the controller of APF (from the initial value $t_{\text {Delay }}=$ $300 \mu \mathrm{s}$ ) to become a new value $t_{\text {Delay }}=120 \mu \mathrm{s}$.

- Case 4: From Case 2, decrease the cut-frequency value of low-pass filter in the controller of APF (from the initial value $f_{\text {Cut-off }}=1200 \mathrm{~Hz}$ ) to become a new value $f_{\text {Cut-off }}=600 \mathrm{~Hz}$.

- Case 5: From Case 2, decrease the length of transmission cable on MV bus (from the initial value $l_{\text {cable }}=50 \mathrm{~km}$ ) to become a new value $l_{\text {cable }}=20 \mathrm{~km}$.

- Case 6: From Case 2, increase the number of DFIGs installed in the wind farm (from the initial value $N_{D F I G}=20$ ) to become a new value $N_{D F I G}=50$.

Morover, in analyzing with Matlab, stability of the overal system is checked again with Nyquist diagram [8]. After that, detailed discussions on the obtained results in this section will be presented in Section 5 .

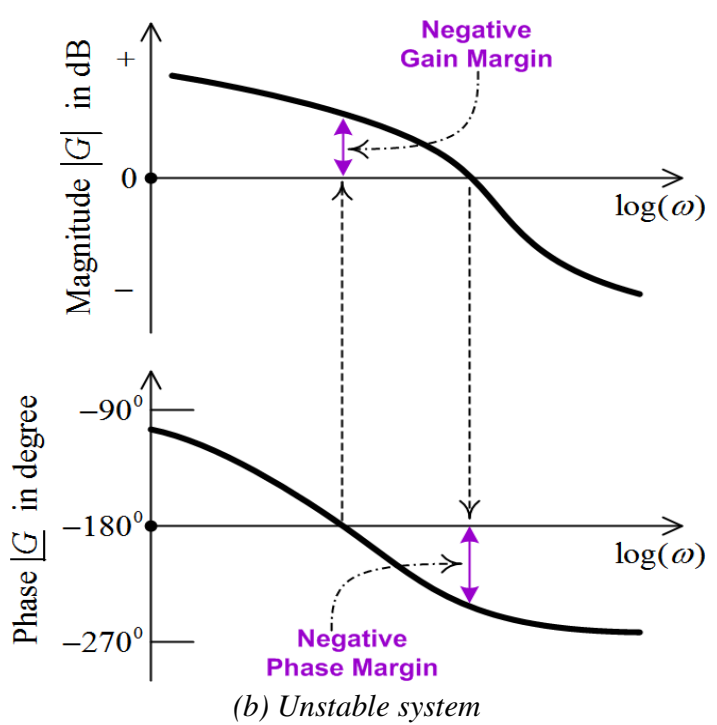

Fig. 4. Theory on stablitiy analysis of control system based on Bode diagram.

A. Case 1: Test with the open-loop controller for APF where $K_{V}=0$ (that means the APF is deactivated) and default initial parameters of the power system. 


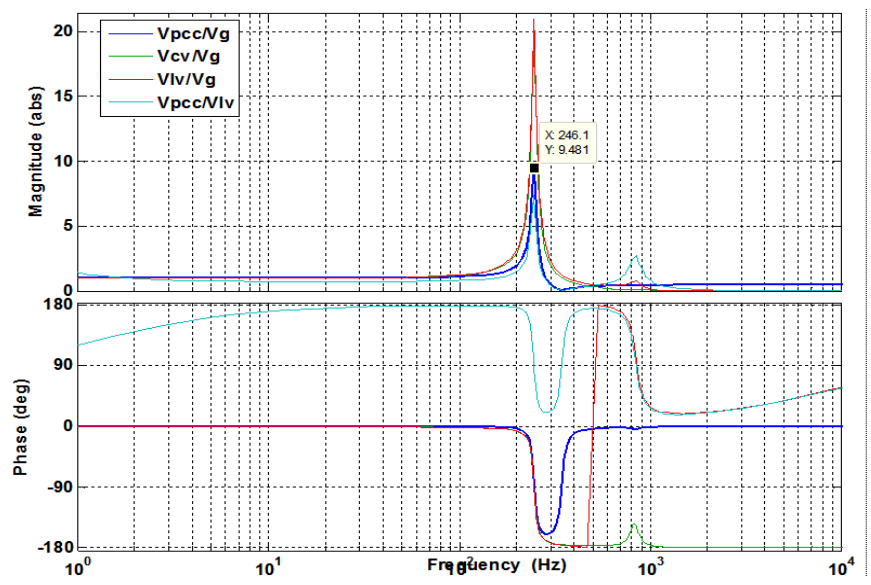

(a) Voltage distortions caused by the voltage source Vg

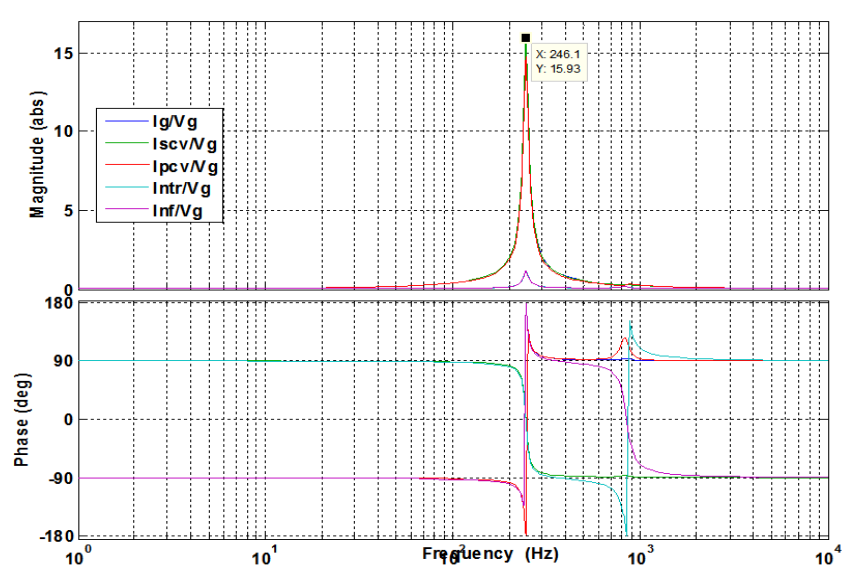

(c) Current distortions caused by the voltage source $\mathrm{Vg}$

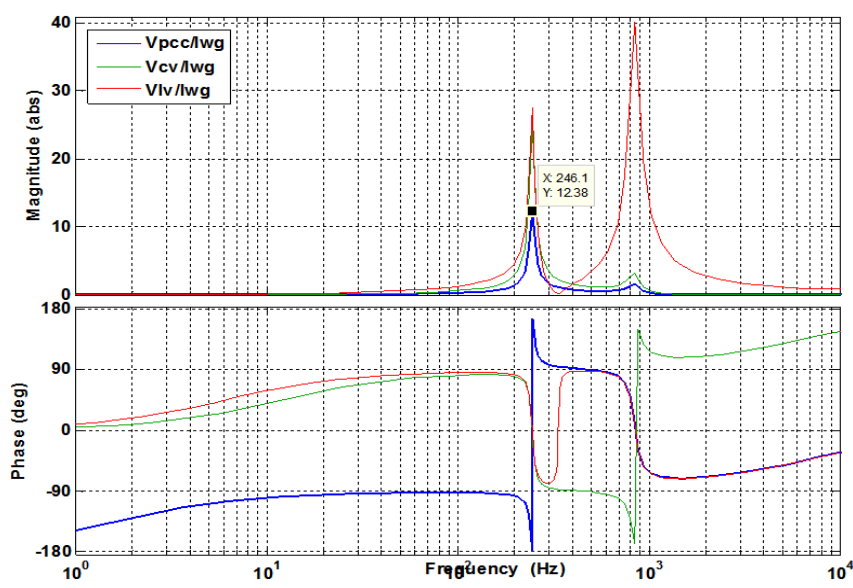

(b) Voltage distortions caused by the current source Iwg

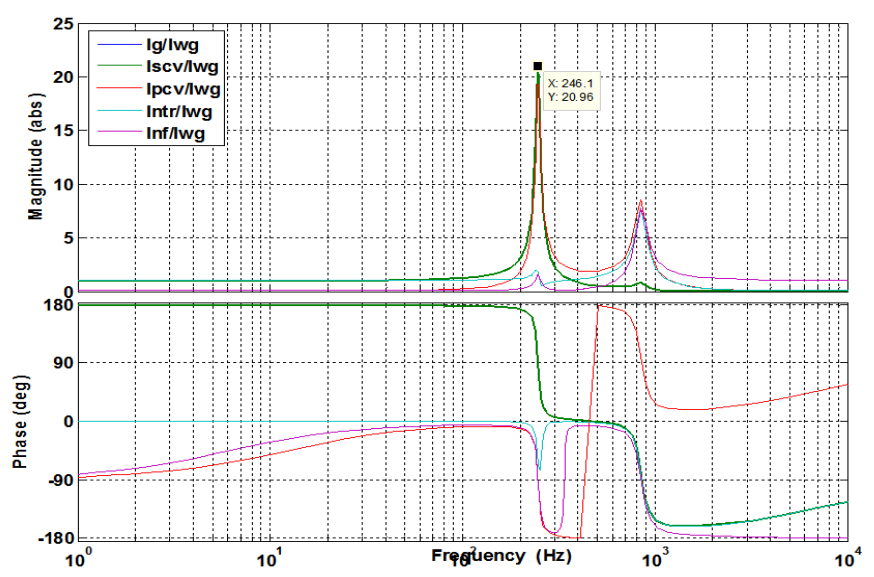

(d) Current distortions caused by the current source Iwg

Fig. 5. Analysis results obtained in Case 1.

B. Case 2: Test with the closed-loop controller where $K_{V}=K_{V-\min }=1.01$ and default initial parameters of power system.

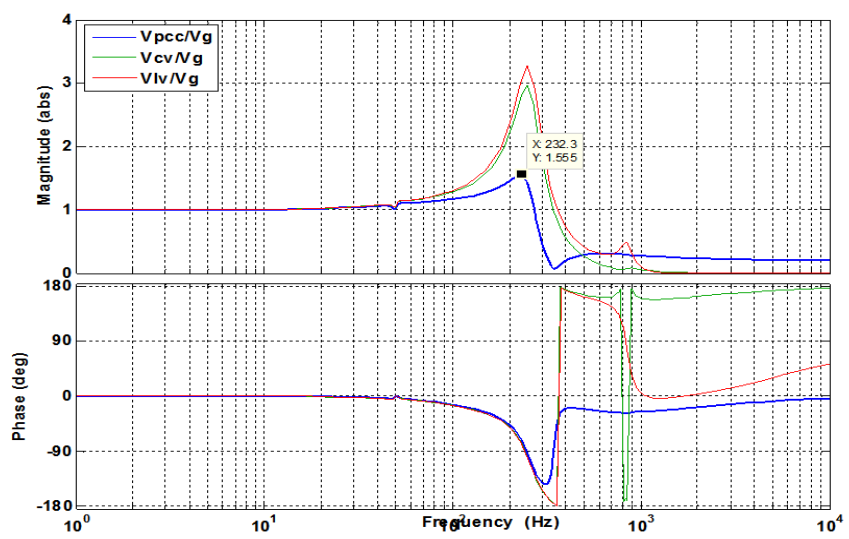

(a) Voltage distortions caused by the voltage source $\mathrm{Vg}$

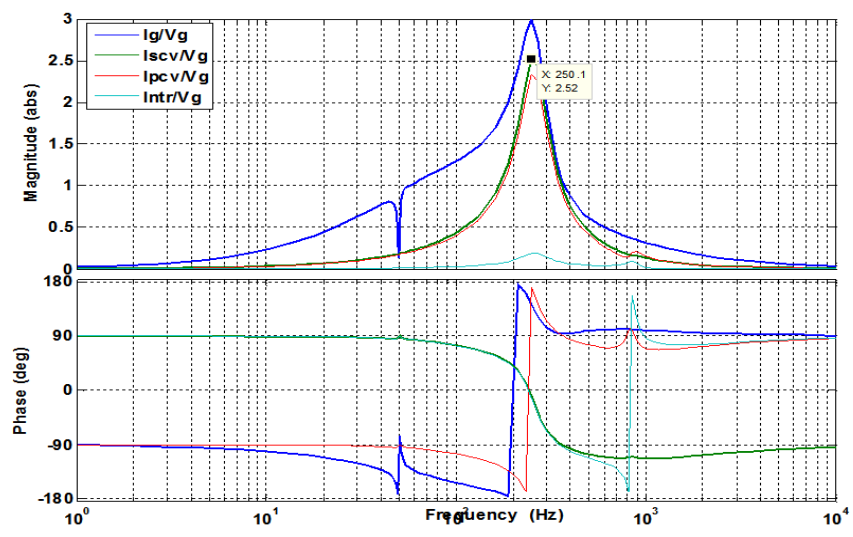

(c) Current distortions caused by the voltage source $V g$

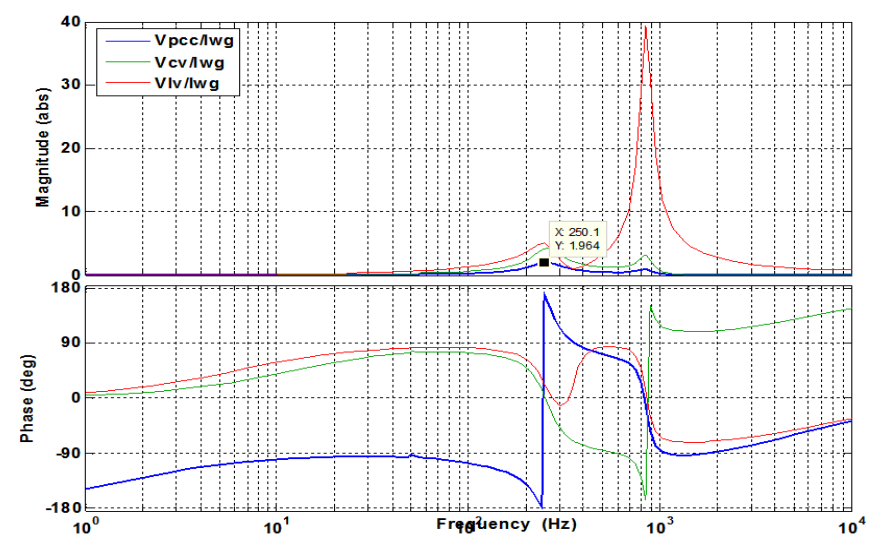

(b) Voltage distortions caused by the current source Iwg

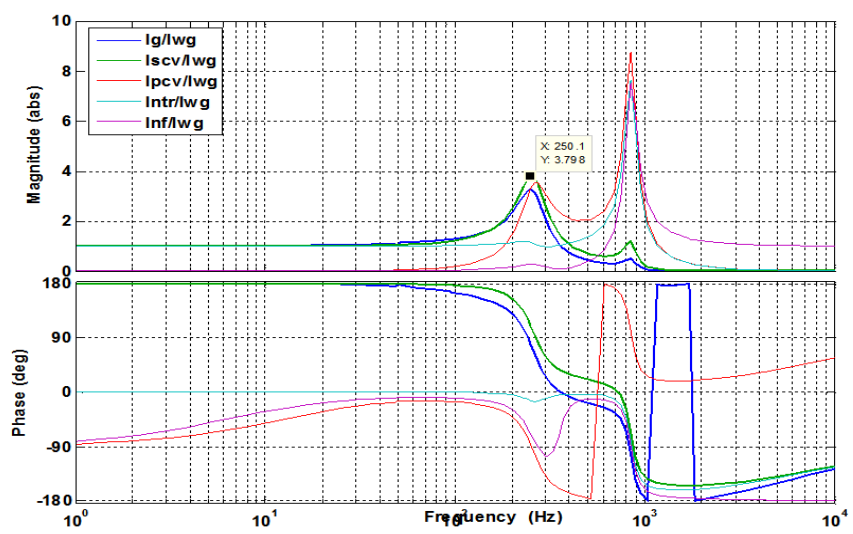

(d) Current distortions caused by the current source Iwg 


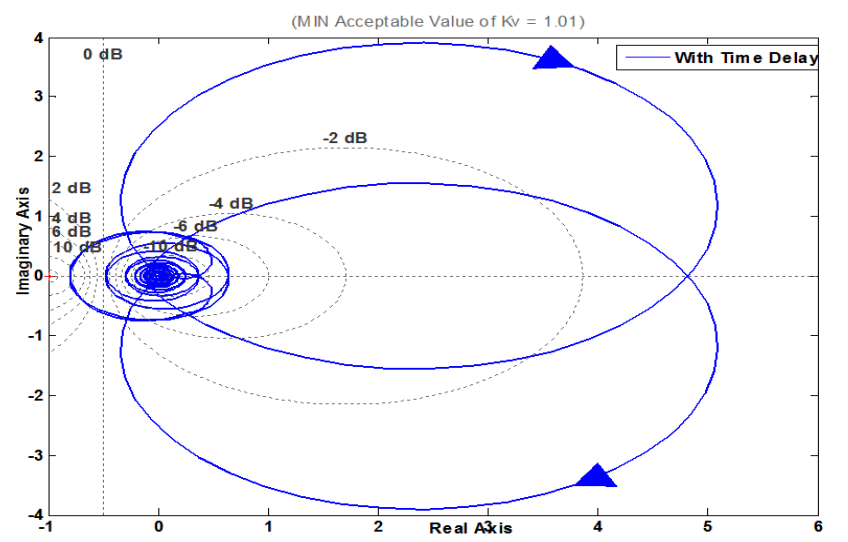

(c) Nyquist diagram of the control system with $K_{V}=K_{V-\min }=1.01$

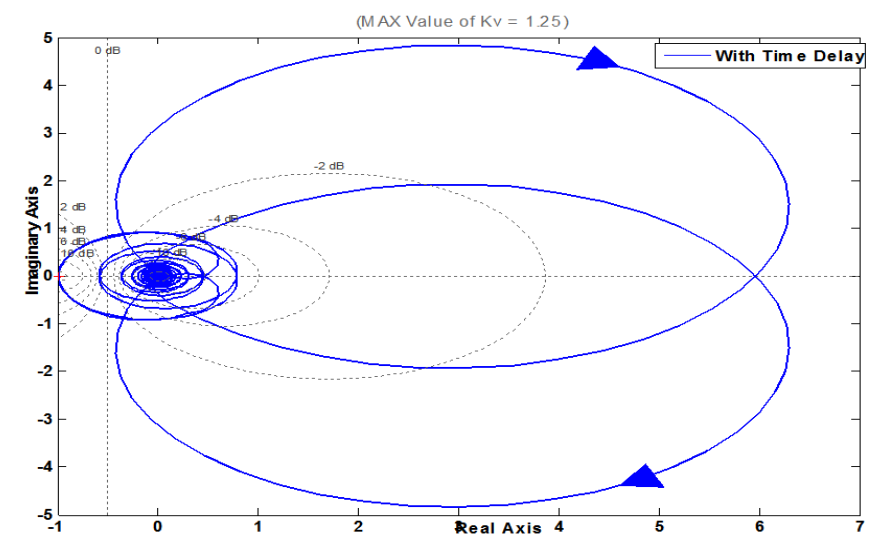

(d) Nyquist diagram of the control system with $K_{V}=K_{V-\max }=1.25$

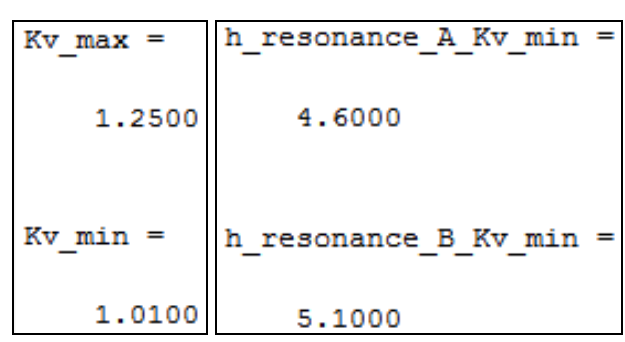

(e) Results obtained from the Matlab program

\begin{tabular}{|c|c|c|c|}
\hline Magnitudes of resonances & $\boldsymbol{K}_{\boldsymbol{V}}=\mathbf{0}$ & $\boldsymbol{K}_{\boldsymbol{V}}=\boldsymbol{K}_{\boldsymbol{V}-\min }=\mathbf{1 . 0 1}$ & Reduction \% \\
\hline $\begin{array}{c}\text { Votage distortions caused by } \\
\text { voltage source Vg }\end{array}$ & $\frac{V_{p c c}}{V_{g}}=9.481$ & $\frac{V_{p c c}}{V_{g}}=1.555$ & $-83.64 \%$ \\
\hline $\begin{array}{c}\text { Votage distortions caused by } \\
\text { current source Iwg }\end{array}$ & $\frac{V_{p c c}}{I_{w g}}=12.38$ & $\frac{V_{p c c}}{I_{w g}}=1.964$ & $-84.14 \%$ \\
\hline $\begin{array}{c}\text { Current distortions caused by } \\
\text { voltage source Vg }\end{array}$ & $\frac{I_{s c v}}{V_{g}}=15.93$ & $\frac{I_{s c v}}{V_{g}}=2.52$ & $-84.18 \%$ \\
\hline $\begin{array}{c}\text { Current distortions caused by } \\
\text { current source Iwg }\end{array}$ & $\frac{I_{s c v}}{I_{w g}}=20.96$ & $\frac{I_{s c v}}{I_{w g}}=3.798$ & $-81.88 \%$ \\
\hline
\end{tabular}

(f) Detailed comparisons on reducing the distortions between Case 1 and Case 2

Fig. 6. Analysis results obtained in Case 2.

C. Case 3: Where the time-delay value in the controller of APF is decreased from $t_{\text {Delay }}=300 \mu s$ to $t_{\text {Delay }}=120 \mu s$.

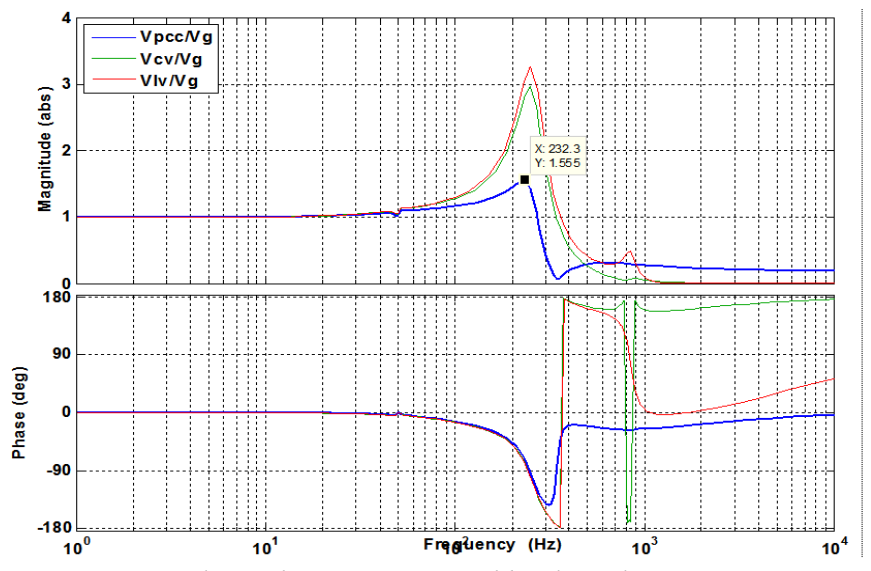

(a) Voltage distortions caused by the voltage source Vg $M$ IN Acceptable Value of $\mathrm{Kv}=1.01$

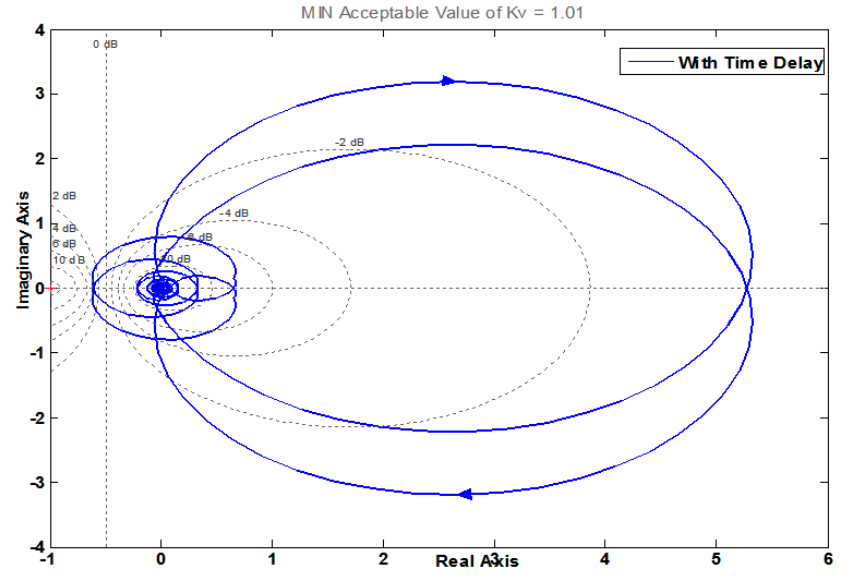

(c) Nyquist diagram of the control system with $K_{V}=K_{V-\min }=1.01$

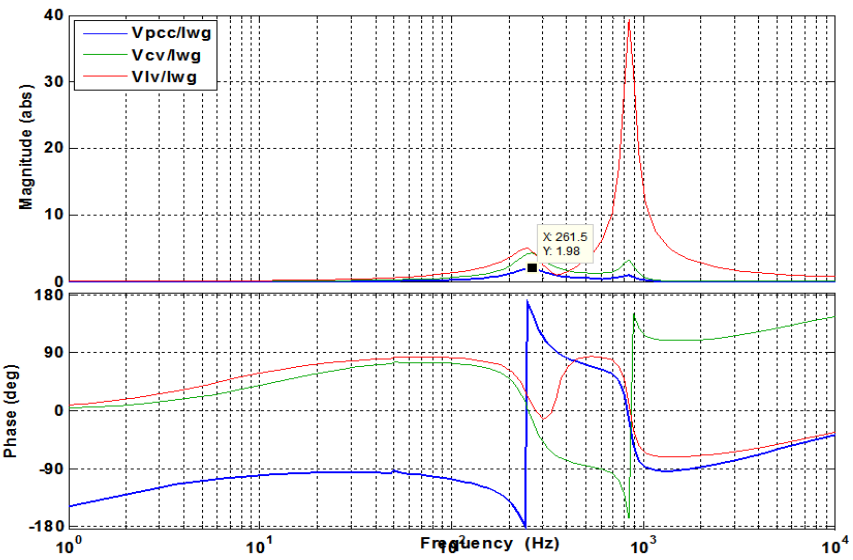

(b) Voltage distortions caused by the current source Iwg

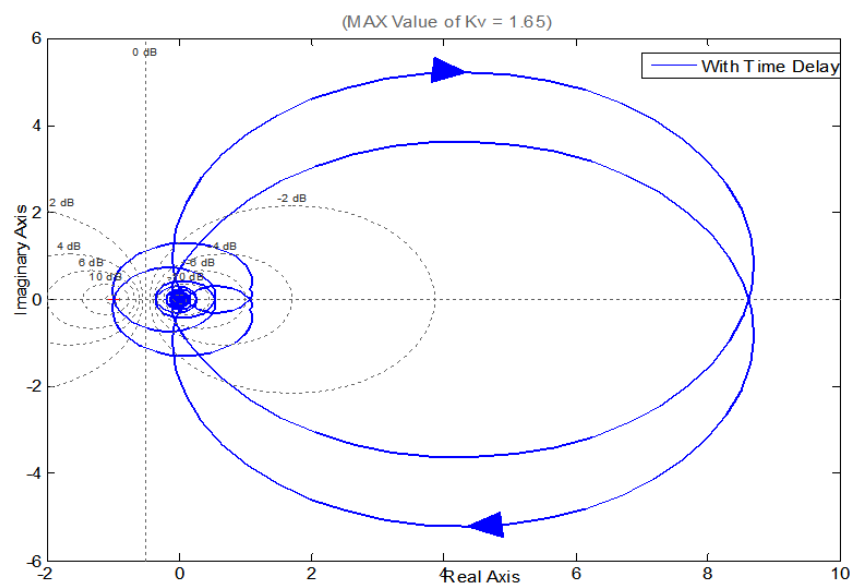

(d) Nyquist diagram of the control system with $K_{V}=K_{V-\max }=1.65$

Fig. 7. Analysis results obtained in Case 3.

D. Case 4: Where the cut-frequency value of low-pass filter in APF is decreased from $f_{\text {Cut-off }}=1200 \mathrm{~Hz}$ to $f_{\text {Cut-off }}=600 \mathrm{~Hz}$. 


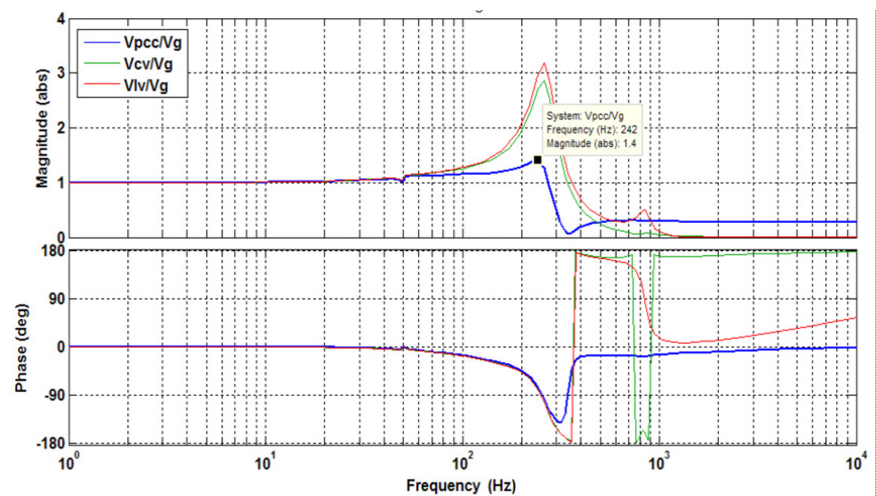

(a) Voltage distortions caused by the voltage source Vg

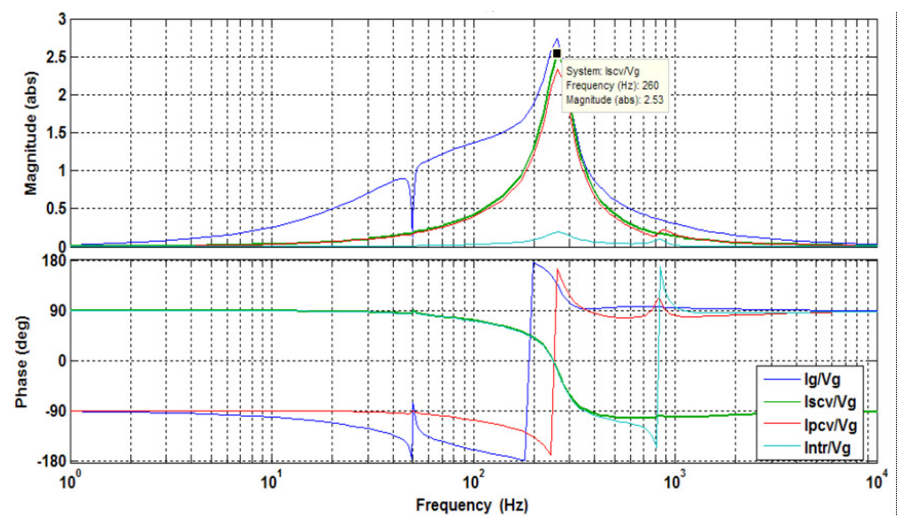

(c) Current distortions caused by the voltage source Vg

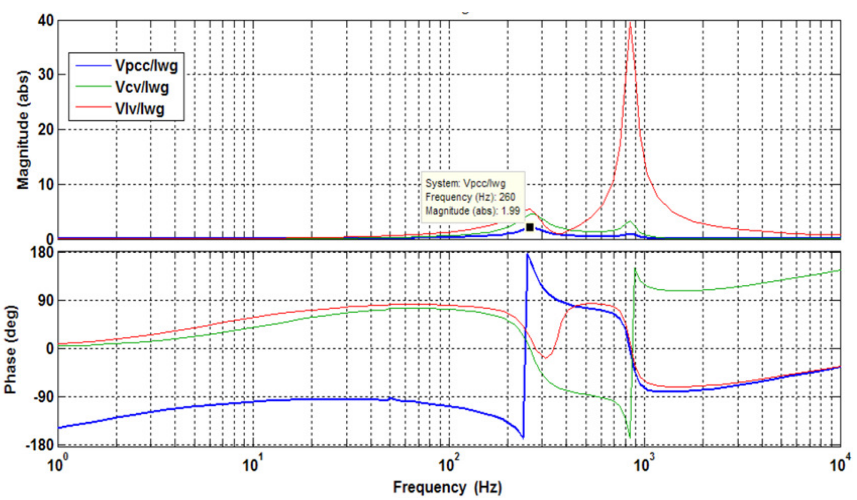

(b) Voltage distortions caused by the current source Iwg

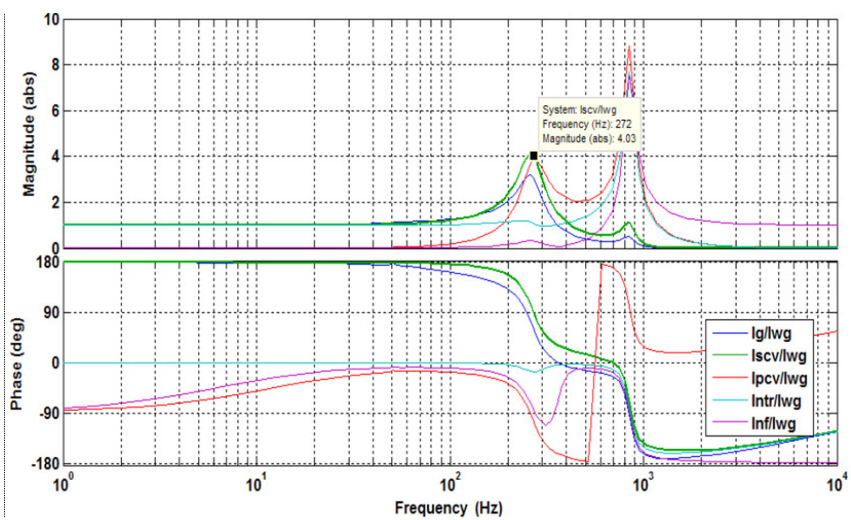

(d) Current distortions caused by the current source Iwg

Fig. 8. Analysis results obtained in Case 4.

E. Case 5: Where the length of transmission cable on the MV bus is decreased from $l_{\text {Cable }}=50 \mathrm{~km}$ to $l_{\text {Cable }}=20 \mathrm{~km}$.

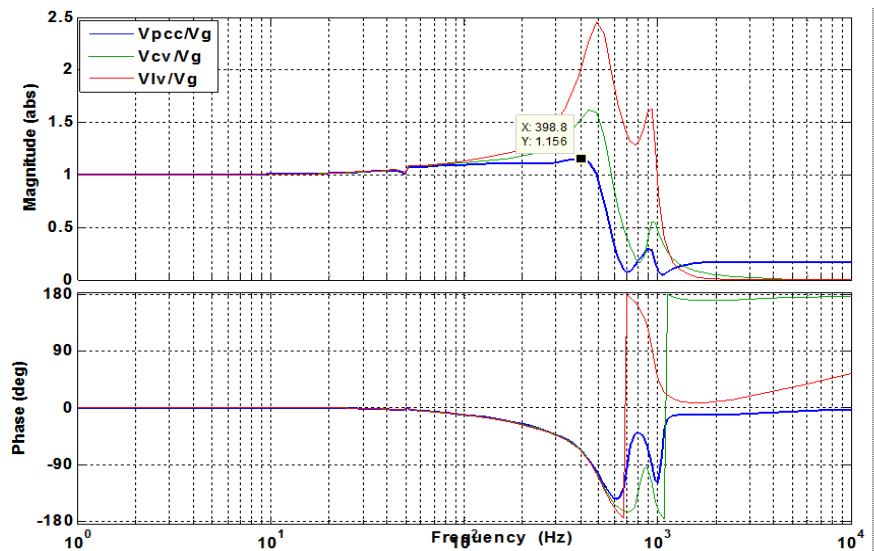

(a) Voltage distortions caused by the voltage source Vg

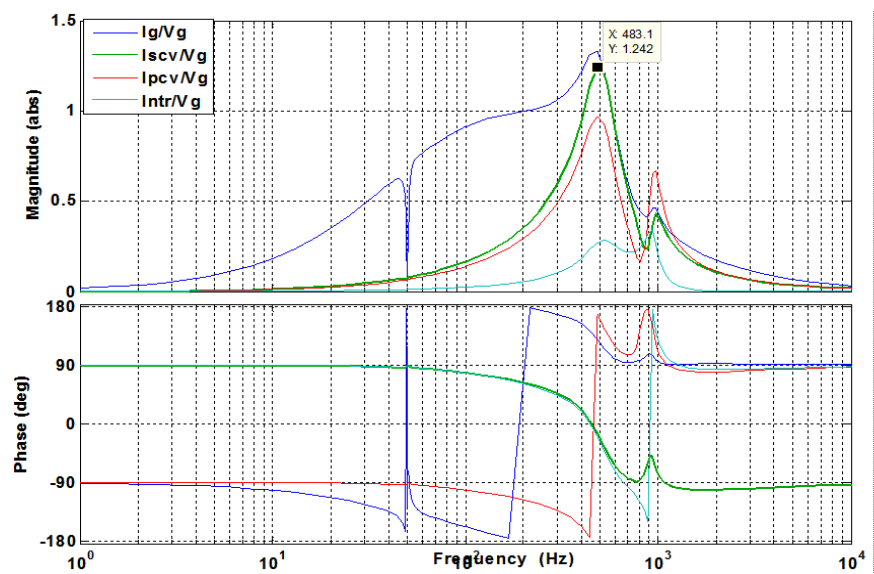

(c) Current distortions caused by the voltage source $\mathrm{Vg}$

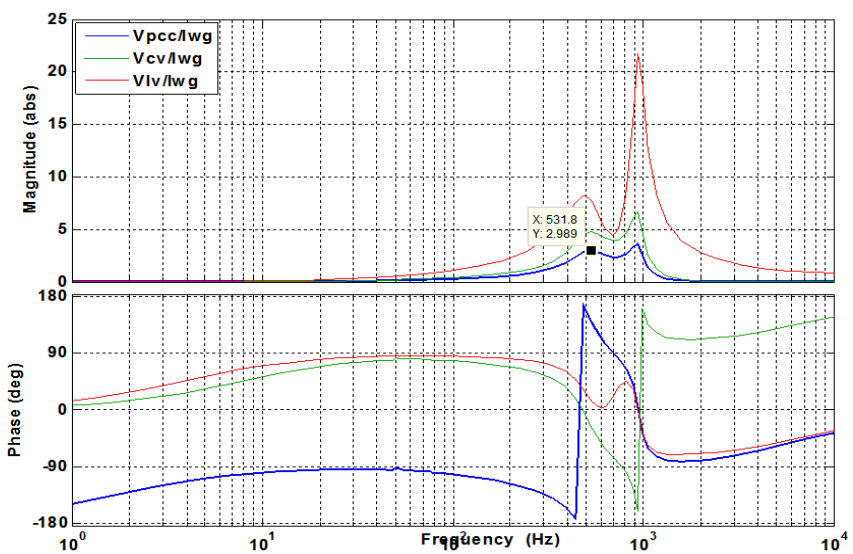

(b) Voltage distortions caused by the current source Iwg

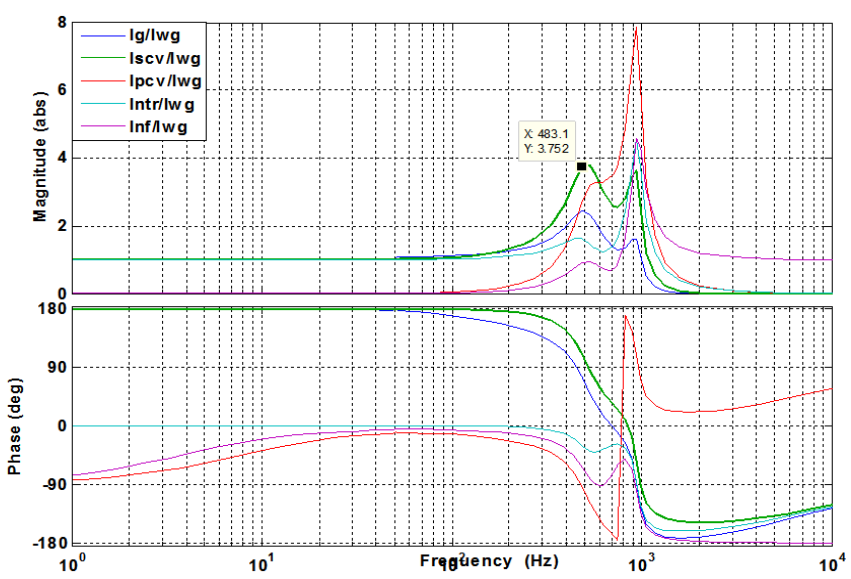

(d) Current distortions caused by the current source Iwg

Fig. 9. Analysis results obtained in Case 5. 
F. Case 6: Where the number of DFIGs installed in the wind farm is increased from $N_{D F I G}=20$ to $N_{D F I G}=50$.
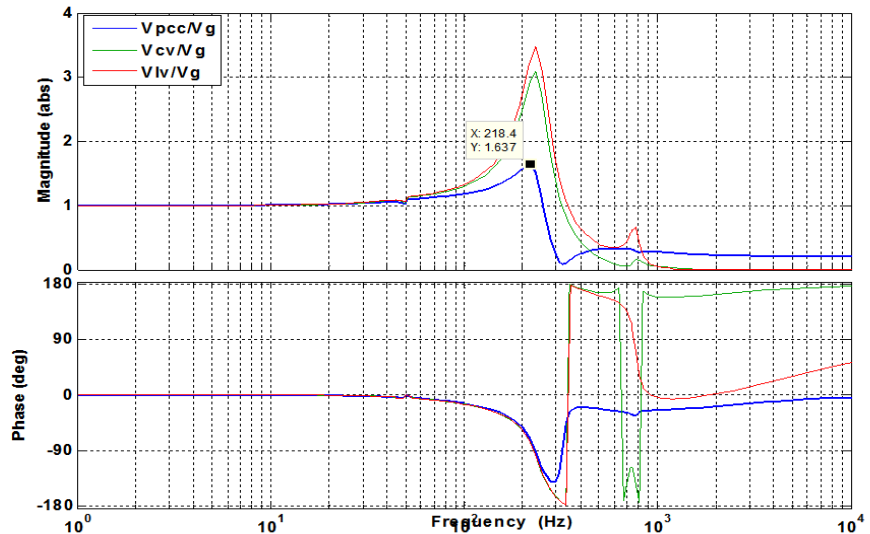

(a) Voltage distortions caused by the voltage source $\mathrm{Vg}$

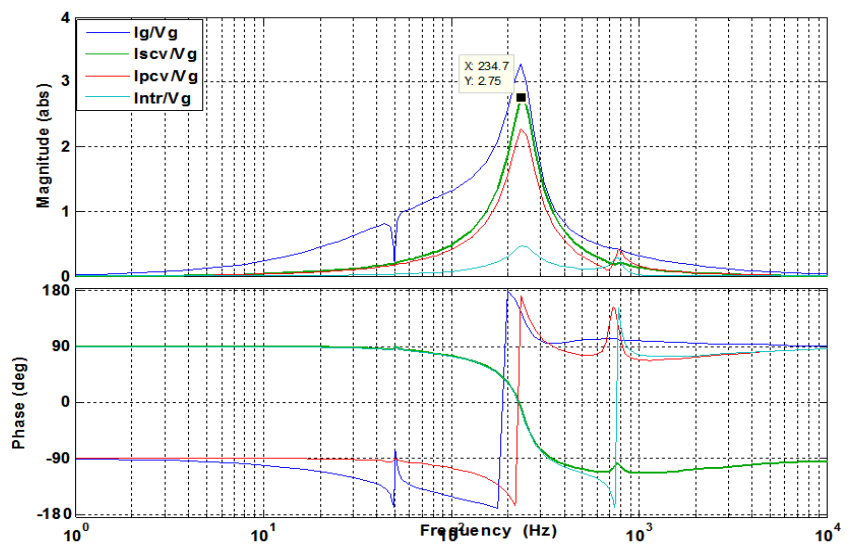

(c) Current distortions caused by the voltage source Vg

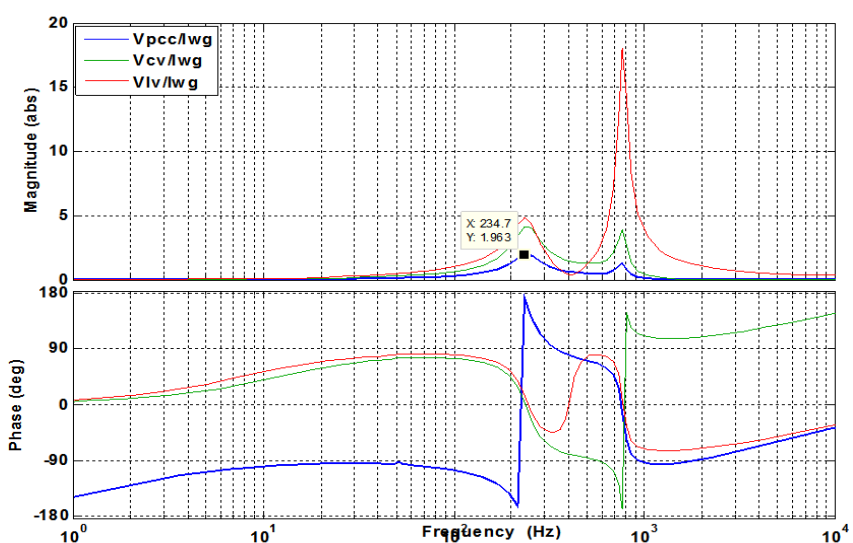

(b) Voltage distortions caused by the current source Iwg

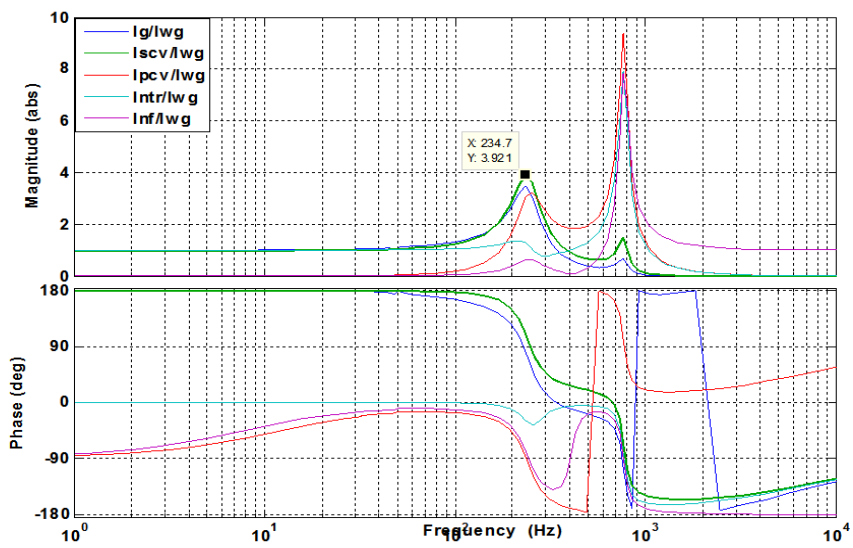

(d) Current distortions caused by the current source Iwg

Fig. 10. Analysis results obtained in Case 6.

Table I. Comparisons on values of $K_{V-\min }$ and $K_{V-\max }$ in Case 2-6

\begin{tabular}{|c|c|c|c|c|}
\hline Case 2 & Case 3 & Case 4 & Case 5 & Case 6 \\
\hline$K_{V-\min }=1.01$ & $K_{V-\min }=1.01$ & $K_{V-\min }=1.15$ & $K_{V-\min }=0.85$ & $K_{V-\min }=0.99$ \\
$K_{V-\max }=1.25$ & $K_{V-\max }=1.65$ & $K_{V-\max }=2.09$ & $K_{V-\max }=1.49$ & $K_{V-\max }=1.25$ \\
\hline In Case 4, if $f_{\text {Cut-off }}=1200 \mathrm{~Hz}$ is increased to $f_{\text {Cut-off }}=1800 \mathrm{~Hz}:$ \\
$K_{V-\min }=0.98 ; \quad K_{V-\max }=0.99$ \\
\hline
\end{tabular}

\section{Discussions}

As given in Figs. 5-6 and especially in Fig. 6(f), the reduction of harmonic resonances around the $5^{\text {th }}$ order $\left(h_{1}\right)$ is generally better when $K_{V}$ is raised. Firstly, $K_{V}$ must be a positive value, and should be chosen in the range of $\left[K_{V-\min } K_{V-\max }\right]$ to have good performance in reducing the magnitudes of resonances and to ensure stability of the control system. Wherein, $K_{V-\max }$ is determined according to the gain-margin and phase-margin values seen in Fig. 4 and [8]; meanwhile, $K_{V-\min }$ can be approximately calculated based on the method introduced in [4] and the background ratio values of the power system according to the two equations (14)-(15) presented in Section 3.

As illustrated in Fig. 7 (Case 3), when the time-delay value of APF is decreased, the value of $K_{V-\min }$ seems to be not changed, but the value of $K_{V-\max }$ is increased fairly much (as compared with Fig. 6 in Case 2). Meanwhile, $h_{1}$ is decreased slightly and $h_{2}$ is almost unchanged.

As shown in Fig. 8 (Case 4) and Table I, when the cut-frequency of the low-pass filter decreased, the value of $K_{V-\min }$ is increased slightly to 1.15 , but the value of $K_{V-\max }$ is increased much to 2.09. Besides, the first order $h_{1}$ is decreased slightly, and the second order $h_{2}$ is almost unchanged. In contrast, if the cut-frequency of low-pass filter increased from $1200 \mathrm{~Hz}$ to $1800 \mathrm{~Hz}$, the value of $K_{V-\min }$ is decreased slightly to 0.98 , but the value of $K_{V-\max }$ is decreased significantly to 0.99 . And we can see that $K_{V-\text { min }}$ now is almost equal to $K_{V-\text { max }}$ in this operation case.

Thus, we can see that the control coefficient $K_{V}$, time delay and cut-frequency of low-pass filter in APF heavily affect stability of the overall control system. Wherein, the coefficient $K_{V}$ clearly has the most important role.

In Case 2 and Case 6 , the $4^{\text {th }}-5^{\text {th }}\left(h_{1}\right)$ and the $16^{\text {th }}-17^{\text {th }}\left(h_{2}\right)$ harmonic resonance orders usually occur. Meanwhile, in Case 5, when the length of transmission cable is decreased, the $8^{\text {th }}-10^{\text {th }}\left(h_{1}\right)$ and the $18.5^{\text {th }}\left(h_{2}\right)$ harmonic resonance orders happen. In all the above cases, the reduction of harmonics around the first order $h_{1}$ 
$\left(4^{\text {th }}-5^{\text {th }}\right.$, or $\left.8^{\text {th }}-10^{\text {th }}\right)$ is much better when $K_{V}$ is increased in the value range of $\left[K_{V-\min } K_{V-\max }\right]$. However, it may be noted that $K_{V}$ does not too much affect the second resonance order $h_{2}\left(16^{\text {th }}-17^{\text {th }}\right.$, or $\left.18.5^{\text {th }}\right)$.

As presented in Fig. 9 (Case 5) and Table I, when the length of cable $l_{\text {Cable }}$ is decreased, the value of $K_{V-\min }$ is decreased from 1.01 (in Case 2) to be 0.85 ; but the value of $K_{V-\max }$ is increased much from 1.25 (in Case 2) to be 1.49. Meanwhile, the first order $h_{1}$ is increased markedly from the $4^{\text {th }}-5^{\text {th }}$ to become around the $8^{\text {th }}-10^{\text {th }}$ order, and the second order $h_{2}$ is just slightly increased from the $16^{\text {th }}-17^{\text {th }}$ to become around the $18.5^{\text {th }}$ order.

As described in Fig. 10 (Case 6) and Table I, when the number of DFIGs in the wind farm $N_{D F I G}$ is increased, the value of $K_{V-\max }$ is unchanged at the value of 1.25 as compared with Case 2, and the value of $K_{V-\min }$ is just decreased very little from 1.01 (in Case 2) to be 0.99 . Besides, all the resonance orders $h_{1}\left(4^{\text {th }}-5^{\text {th }}\right)$ and $h_{2}$ $\left(16^{\text {th }}-17^{\text {th }}\right)$ are almost not varied in their values as compared with Case 2.

Besides, it is noted that the value for $K_{V-\min }$ will be varied if the threshold values in (14)-(15) are changed according to configuration of the power system; and as mentioned in [1], the second resonance order $h_{2}$ is heavily affected by the design structure of R-C filter at each DFIG.

\section{Conclusion}

This paper has presented an analysis about impacts of main design parameters in the controller for APF on stability of the electric grid where a megawatt DFIG wind farm and APF are connected. Wherein, the proportional coefficient $K_{V}$ is noted as the most important parameter in the controller of APF. This means that the reduction of harmonic voltage is generally better when the value of $K_{V}$ is increased in its stable value range. Moreover, the technique, utilized to determine the stable value range ( $\left.0<K_{V} \leq K_{V-\max }\right)$ and the suitable-performance value range ( $K_{V-\min } \leq K_{V} \leq K_{V-\max }$ ), also has been proposed and evaluated in this research. As well, the newly developed Matlab program can automatically analyze and determine well the important parameters: $K_{V-\min }, K_{V-\max }$, and $h_{1}$ (the orders of voltage and current distortions).

In our next study, automatically online fine-tuning the control coefficient $K_{V}$ in APF $[14,15]$ not only to achieve good performance but also to ensure stability within operating conditions and unexpected parametric changes of the power grid, using wind farms, will be considered.

\section{References}

[1] N. G. M. Thao, K. Uchida, K. Kofuji, T. Jintsugawa, and C. Nakazawa, "A Comprehensive Analysis Study about
Harmonic Resonances in Megawatt Grid-Connected Wind Farms," Proceedings of ICRERA 2014, pp. 387-394, Milwaukee, USA, 19-22 Oct 2014.

[2] H. Akagi, "Control Strategy and Site Selection of a Shunt Active Filter for Damping of Harmonic Propagation in Power Distribution Systems", IEEE Transactions on Power Delivery, Vol. 12, No. 1, pp. 354-363, Jan 1997.

[3] Z. H. Yuan and Y. Du, "Analytical Analysis of Shunt Active Power Filters Based on Voltage Detection", Proceedings of IAS 2005, Vol 2, pp. 1241-1245, Oct 2005.

[4] H. Akagi, H. Fujita, and K. Wada, "A Shunt Active Filter based on Voltage Detection for Harmonic Termination of a Radial Power Distribution Line", IEEE Transactions on Industry Application, Vol. 35, No. 3, pp. 638-645, May/June 1999 .

[5] K. Wada, H. Fujita, and H. Akagi, "Considerations of a Shunt Active Filter based on Voltage Detection for Installation on a Long Distribution Feeder", Proceedings of IAS 2001, Vol. 1, pp. 157 - 163, October 2001.

[6] W. C. Santana, K. Al-Haddad, and L. E. B. Da Silva, "Modeling and Active Damping of Harmonic Propagation on Electric Distribution Systems", Proceedings of EPEC 2009, pp. 1-7, October 2009.

[7] D. Bula and M. Pasko, "Stability Analysis of Hybrid Active Power Filter", Bulletin of The Polish Academy of Sciences -Technical Sciences, Vol. 62, No. 2, pp. 279-286, June 2014.

[8] G. Vinnicombe, "Feedback Stability and the Nyquist Diagram", Linear Systems and Control course - Handout 6.

[9] P. Jintakosonwit, H. Fujita, and H. Akagi, "Control and Performance of a Fully-Digital-Controlled Shunt Active Filter for Installation on a Power Distribution System", IEEE Transactions on Power Electronics, Vol. 17, No. 1 , pp. 132-140, January 2002.

[10] P.S. Sensarma, K.R. Padiyar, and V. Ramanarayanan, "A Comparative Study of Harmonic Filtering Strategies for a Shunt Active Filter", Proceedings of IAS 2000, Vol. 4, pp. 2509-2516, October 2000.

[11] W. Longhui, Z. Fang, Z. Pengbo, L. Hui, W. Zhaoan, "Stability Analysis and Controller Design of Hybrid Compensation System with Parallel Active Power Filter and Parallel Capacitors", Proceedings of PESC 2007, pp. 1105-1111, June 2007.

[12] S. Srianthumrong, H. Fujita, and H. Akagi, "Stability Analysis of a Series Active Filter Integrated With a Double-Series Diode Rectifier", IEEE Transactions on Power Electronics, Vol. 17, No. 1, pp. 117-124, Jan 2002.

[13] X. Wang, "Harmonic Stability in Wind Power Plants", Abstract of project in Aalborg University, Denmark, 2014.

[14] P. Jintakosonwit, H. Akagi, H. Fujita, and S. Ogasawara, "Implementation and Performance of Automatic Gain Adjustment in A Shunt-Active Filter for Harmonic Damping Throughout A Power Distribution System", IEEE Transactions on Power Electronics, Vol. 17, No. 3, pp. 438-447, May 2002.

[15] P. Jintakosonwit, H. Akagi, H. Fujita, and S. Ogasawara, "Implementation and Performance of Cooperative Control of Shunt Active Filters for Harmonic Damping Throughout a Power Distribution System", IEEE Transactions On Industry Applications, Vol. 39, No. 2, pp. 556-564, March/April 2003. 